\title{
MÉTODOS ADEQUADOS DE SOLUÇÃO DE CONFLITOS DA JUSTIÇA RESTAURATIVA FRENTE AO NOVO CÓDIGO DE PROCESSO CIVIL
}

\author{
Guilherme Calmon Nogueira da Gama ${ }^{1}$ \\ Maria Lúcia Sucupira Medeiros ${ }^{2}$
}

\begin{abstract}
Resumo
O artigo objetiva discutir as alternativas oferecidas pelo Código de Processo Civil em vigor (CPC) para resolução de conflitos, identificando, analisando e discutindo a cooperação trazida por ele nas disputas judiciais entre as partes envolvidas, enfocando mais detidamente os métodos de conciliação e mediação, além dos seus impactos junto às partes interessadas, com ênfase na justiça informal e seus reflexos no acesso à justiça. Neste sentido, busca-se verificar os efeitos destes métodos na perspectiva da justiça restaurativa, em comparação com a justiça retributiva, mediante a conceituação elaborada pela doutrina. Além disso, toma como parâmetros aspectos relativos à Administração Pública brasileira, ensejando a crítica dos modelos adotados antes da vigência do novo diploma legal. A partir desta crítica, propõe uma discussão sobre a viabilidade de se incentivar a solução de conflitos nos moldes oferecidos pelo Novo CPC.
\end{abstract}

Palavras-Chave: Direito Processo Civil; solução de conflitos; conciliação; mediação; justiça retributiva; justiça restaurativa; Administração Pública.

\section{INTRODUÇÃO}

Em vigor desde março de 2016, o Novo Código de Processo Civil trouxe, como aperfeiçoamento da prática jurídica no acesso à justiça, a "obrigatoriedade" da realização de audiência de conciliação ou mediação, a partir do artigo 334, corroborando e dando exequibilidade ao previsto no artigo $3^{\circ}, \mathbb{3} 3^{\circ}$, do referido Código, ao expressar o seguinte: "A conciliação, a mediação e outros métodos de solução consensual de conflitos deverão ser estimulados por juízes, advogados, defensores públicos e membros do Ministério Público, inclusive no curso do processo judicial”.Por outro lado, o $\$ 2^{\circ}$ do mesmo artigo prevê que "o Estado promoverá, sempre que possível, a solução consensual dos conflitos", a ser viabilizada, inclusive, pelos "centros judiciários de solução consensual de conflitos, responsáveis pela realização de sessões e audiências de conciliação e mediação pelo desenvolvimento de programas destinados a auxiliar, orientar e estimular a

\footnotetext{
${ }^{1}$ Doutor em Direito Civil pela Universidade do Estado do Rio de Janeiro. Professor Associado de Direito Civil pela UERJ. Professor Permanente do Programa de Pós-Graduação em Direito da Universidade Estácio de Sá (RJ). Professor da EMARF e EMERJ. Pesquisador do CNPq. E-mail: gcalmon@trf2.gov.br

${ }^{2}$ Doutoranda em Direito pela Universidade Estácio de Sá. Pesquisadora em formação do grupo de pesquisa Observatório de Políticas Públicas, Direito e Proteção Social (PPGD-UNESA). Coordenadora do Núcleo de Prática Jurídica do Centro Universitário Moacyr Sreder Bastos. Professora titular de Direito Tributário, Laboratório de Prática Jurídica Civil I e II e Tópicos Especiais em Educação para o curso de Pedagogia (direito educacional).E-mail: gabgn@trf2.jus.br
} 
autocomposição" (artigo 165).

Com base nestas formulações que revelam a expressiva flexibilidade inovada no bojo do dispositivo de lei em comento, a abordagem deste artigo se inicia pela contextualização histórica do acesso à justiça, mostrando como estes procedimentos vinham ocorrendo ao longo dos tempos antes do CPC atualmente em vigor. Em seguida, éfeito um estudo comparativo entre a justiça restaurativa e retributiva, visando a mostrar o papel da primeira no sentido de propiciar a aplicação dos métodos consensuais para a resolução dos conflitos.

No tópico referente à atuação da Administração Pública são tecidos alguns comentários sobre a prática insuficiente destes métodos, que parece ainda não estar consolidada entre as partes em conflito, quando a Administração se encontra presente em um dos polos da demanda, perdendo-se a oportunidade de uma utilização que traga resultados mais positivos destes métodos. Tal necessidade também se destaca quando se trata do tópico voltado para discutir o incentivo da solução de conflitos por meios adequados de solução de conflitos trazidos pelo CPC em vigor.

Nas considerações finais, são desenvolvidas as conclusões sobre os conteúdos enfocados, cuja complexidade abre novas possibilidades de abordagem para o efetivo esclarecimento da matéria.

\section{CONTEXTUALIZAÇÃO HISTÓRICA DO ACESSO A JUSTIÇA}

O acesso à justiça não pode ser compreendido senão contextualizado dentro da evolução histórica pela qual passou ao longo dos tempos, à semelhança da própria evolução sociopolítica do Estado brasileiro. J. Guilherme de Aragão (1955, p. 5-6) leciona que a dualidade de jurisdição, no Império, se realizou por meio do Conselho de Estado, órgão do Poder Moderador que se pronunciava a respeito das demandas existentes entre os particulares e a Administração Pública e que se tornou um órgão jurisdicional, a partir do Regulamento n 124, de 5 de fevereiro de 1842 .

Nesta época a autoridade administrativa prevalecia sobre a judiciária. Mais tarde ambas se separaram, com base nas doutrinas e na jurisprudência da época. Em decorrência desta situação, a delimitação da competência dependia de critérios acidentais e empíricos, o que gerou a interferência dos recursos administrativos incipientes no processo civil então vigente (ARAGÃO, 1955, p. 17).

Durante a República, a questão evoluiu no sentido de se erigir um princípio, segundo o qual "o controle judiciário incide sobre o ato administrativo ilegal, se a ilegalidade atenta contra direito individual ou dirime litígio entre a administração e os particulares" (ARAGÃO, 1955, p. 24). Com este movimento, o Judiciário começa a angariar ainda maior importância na proteção dos direitos individuais, com o surgimento de institutos como o mandado de segurança e o habeascorpus, instrumentos necessários para proporcionar essa proteção.

Mas o acesso à justiça surge em sua plenitude com o direito em discussão, no qual os instrumentos mencionados não bastam, mas a necessidade de uma ação em juízo. Assim, se constitui outro nexo entre as 
relações das autoridades judiciárias e administrativas, mediante o qual se firma agora a superioridade da instância judiciária sobre a administrativa, chegando à unidade jurisdicional. Com esta unidade, se atribuiu o monopólio da função jurisdicional às autoridades judiciárias e, também, se assegurouprioridade e eficácia definitiva às suas decisões (ARAGÃO, 1955, p. 32-35).

Diante da autonomia e interdependência dos poderes, houve uma imposição de equilíbrio, denominada por J. Guilherme de Aragão (1955, p. 43) de "solução de síntese entre a autonomia da ação administrativa e o controle jurisdicional". Com a necessidade de se manter o equilibrio entre as duas esferas apontadas, o processo, instrumento do acesso à justiça, precisa ser aplicado com total isenção de seu condutor, o juiz, a fim de se evitar um retorno àquelas interferências apontadas pelo mesmo autor.

No entanto, não se pode desprezar o enfoque de Mauro Cappelletti com relação ao acesso à Justiça, inclusive no que diz respeito à assistência judiciária. Na sua visão, o acesso é vital para as pessoas sem condição financeira de custear o processo e o nascimento da representação jurídica dos interesses difusos, mas ultrapassando estas duas "ondas", "numa tentativa de atacar as barreiras ao acesso de modo mais articulado e compreensivo". Em que pese o autor se mostrar entusiasmado com o direito do acesso à assistência judiciária pelos pobres, produto da consciência social da década de 1960 e a representação dos interesses difusos, constata que o Estado não se preocupou em garantir o direito conquistado, quando afirma: "O direito ao acesso foi, assim, reconhecido e se the deu algum suporte, mas o Estado não adotou qualquer atitude positiva para garanti-lo" (CAPPELLETTI; GARTH, 1998, p. 31; 32).

Antes de focar o acesso à justiça, mas já delineando o seu alargamento, o autor se referiu ao sistema judicare como uma grande realização das reformas na assistência judiciária, pois esta última se estabeleceu como um direito para as pessoas previstas na lei. No entanto, Cappelletti comenta a criação do judicare de forma genérica, aplaudindo sua contribuição à assistência judiciária, mas não o elevou a nível mais amplo, pois identificou que o sistema é falho, na medida em que "ele confia aos pobres a tarefa de reconhecer as causas e procurar auxílio; não encoraja, nem permite que o profissional individual auxilie os pobres a compreender seus direitos e identificar as áreas em que se podem valer de remédios jurídicos" (CAPPELLETTI; GARTH, 1998, p. 38).

Ainda não foi com este instituto do judicareque os pobres conseguiram reivindicar seus direitos em áreas que tenham barreiras geográficas e culturais, as quais vão refletir na relação entre o advogado e o pobre. Não é só isto, pois, ao comentar a diferença entre as pessoas pobres e os advogados, o autor compara: "É evidente que a representação através de profissionais particulares não enfrenta as desvantagens de uma pessoa pobre frente a litigantes organizacionais"(CAPPELLETTI; GARTH, 1998, p. 28).Eduardo Juan Couture (1995, p. 98) complementa as ideias de Cappelletti, quando afirma que "o direito pode criar um sistema perfeito, no tocante à justiça; mas se este sistema for aplicado, em última instância, por homens, o direito valerá o que valham estes 
homens".

Cappelletti aborda ainda outro modelo de assistência judiciária, por meio de advogados pagos pelos cofres públicos, que se diferem do sistema judicare, pois estes advogados ficarão incumbidos de assistir aos pobres enquanto pertencentes a uma classe.Esse sistema de assistência jurídica empreende esforços para conscientizar os pobres de seus novos direitos. Segundo o autor, o sistema deixa ainda as pessoas pobres "desejosas de utilizar advogados para ajudar a obtê-los". O sistema, porém, foi além, pois "ataca outras barreiras ao acesso individual. Ele pode apoiar os interesses difusos ou de classe das pessoas pobres". O autor comenta que o programa se dirige aos pobres e tem a finalidade de mostrar seus direitos, direitos estes que, para serem dos pobres, necessitam de advogados eficientes para defendê-los, enquanto classe. Acontece que, nesse diapasão, o governo tem de apoiar e dotar atividades de natureza política junto aos pobres, as quais serevertem contra o próprio governo (CAPPELLETTI; GARTH, 1998, p. 40).

Outro problema que impede o real acesso à justiça é a representação dos interesses difusos dos pobres enquanto classe, pois, conforme afirma Cappelletti, "a concepção tradicional do processo civil não deixava espaço para a proteção dos direitos difusos". Os litígios que abrangem um número grande de pessoas caracterizam o movimento mundial em direção aos litígios de Direito Público. Segundo o autor, foi preciso se transformar o papel do juiz e conceitos básicos com a nova concepção social e coletiva dos direitos dos pobres enquanto classe, pois muitas vezes estes direitos se viram contra o próprio Estado(CAPPELLETTI; GARTH, 1998, p. 79).

Segundo Aluísio Gonçalves de Castro Mendes, "o desequilíbrio entre as partes pode ser, também, por outro lado, um fator decisivo para que a pessoa lesada deixe de buscar individualmente a proteção judicial[...]””. Adiante, o mesmo autor afirma que "as ações coletivas, se bem estruturadas, podem ser, portanto, um efetivo instrumento para o aperfeiçoamento do acesso à Justiça, eliminando os entraves relacionados com os custos processuais e o desequilíbrio entre as partes" (MENDES, 2014, p. 36; 37).

Ampliando o tema desta discussão, Ricardo Perlingeiro Mendes da Silva aponta a origem de um litígio de direito público de massa, a partir de um ato material da administração ou ato administrativo, que, representando uma atuação ou omissão administrativa, resulte dano a toda a sociedade ou a um segmento seu, podendo atingir direitos de inúmeras pessoas (SILVA, 2007, p. 923-924).

Perlingeiro destaca a conquista da ação popular ao afirmar que ela, de forma democrática, assegura o controle da moralidade e legalidade administrativa. Da mesma forma, Fernando de Castro Fontainha cita que este remédio foi a única menção feita ao Brasil no relatório geral do projeto de Florença, realizado por Cappelletti e Garth. O autor destaca que a ação popular fundamentou o estudo de Cappelletti e Garth que a deram como exemplo de defesa dos interesses difusos (FONTAINHA, 2009, p. 79; 80).

Frise-se que a impugnação de um ato administrativo individual pode adquirir uma forma coletiva se estiver 
calcada em fato relativo à coletividade, como afirma Ricardo Perlingeiro, significando que isto acontece quando a impugnação se funda em interesse difuso ou coletivo. Quanto aos litígios de massa, "necessário se faz uma reflexão sobre os procedimentos judiciais existentes", continua o mesmo autor, a fim de se evitar os inconvenientes. Ele indica ainda a adoção de súmulas e precedentes judiciais que vinculem os juízes quanto à matéria comum, mas ressalta que todo cidadão tem direito ao devido processo legal, numa clara demonstração de que as ações podem ser propostas individualmente, embora tratem dos interesses coletivos (SILVA, 2007, p. 930-931).

Fernanda Tartuce (2015, p. 77) afirma que "o cerne do acesso à justiça não é possibilitar que todos possam ir à corte, mas sim que a justiça possa ser realizada no contexto em que se inserem as partes, com a salvaguarda da imparcialidade da decisão e da igualdade efetiva das partes".

Diante desse quadro histórico, torna-se difícil constatar se as ideias de conciliação ou mediação trazidas pelo Novo Código vão suprir as dificuldades e aineficiência do acesso à justiça e, o que é pior, saber se os pobres conseguirão alcançar uma igualdade frente às outras classes no acesso e no resultado.

\section{JUSTIÇA RETRIBUTIVA VERSUS JUSTIÇA RESTAURATIVA}

A resolução de conflitos no âmbito jurídico, via de regra, tem ocorrido a partir do castigo ou da reparação penal mediante intervenção da justiça: "O castigo se fundamenta no sofrimento e a reparação na busca de acordos para refazer o que foi danificado ou afetado no conflito" (COLORADO, 2013, p.119). Entende-se que este é o procedimento mais comum adotado no Estado Moderno, tornando-se o cerne da justiça retributiva: o delinquente tem de pagar com a perda de seus direitos, cumprindo sanções que muitas vezes trazem consequências que extrapolam a gravidade do crime cometido e afronta seus direitos humanos, seja na dosimetria da pena, seja nos locais destinados ao cumprimento da pena.

As desigualdades trazidas pelo Estado Liberal, em decorrência do aspecto econômico que gerou acumulação de riquezas para alguns, fizeram surgir aspectos sociais importantes para os quais o Estado dava proteção. A modernização levou a uma reorganização social, praticada,por exemplo, pelas organizações não governamentais (ONGs), de se concretizar a igualdade no plano social.

Em função da reorganização social, surge a necessidade da reestruturação no âmbito jurídico, implicando também o surgimento do conceito de justiça restaurativa adotado pelo jurista colombiano Fernando Diaz Colorado, mediante o qual ela se apresenta como um "modelo alternativo de enfrentamento do crime que, em vez de se fundar na ideia tradicional de retribuição ou castigo, parte da importância que tem para a sociedade a reconciliação entre vítima e agressor". Com isso, adquire uma intenção mais humanizadora na qual busca-se a aplicação do princípio da dignidade humana, reclamando o reconhecimento do outro como sujeito de direitos e participante pleno das decisões nas quais possa estar sendo prejudicado e não contemplado (COLORADO, 
2013, p. 121;160).

Percebe-se, pelo próprio modelo antigo de crime com retribuição de pena utilizado ao longo dos tempos, a necessidade de se implementarem mudanças nos procedimentos da justiça no mundo ocidental, por serem exclusivamente calcados na lei, não acompanhando, assim, a evolução social transformadora do mundo, desde os tempos em que havia os privilégios da aristocracia e do clero. Foi assim que surgiram pesquisas na área da vitimologia, pressupondo programas de assistência às vítimas, no sentido de considerá-las como fator importante de compreensão dos fenômenos criminais, corrente defendida pelo criminólogo espanhol Antonio Garcia-Pablos de Molina, ao considerar que a criminologia tem de abordar em seus estudos a vítima dos crimes com o objetivo de privilegiar a aplicação de práticas restaurativas na solução de conflitos resultantes do crime. Para o mesmo autor, o pensamento vitimológico leva a considerar a vítima como sujeito passivo dentro do processo penal retributivo, para considerá-la como sujeito ativo portadora de plenos direitos sem desprezar os direitos do delinquente (COLORADO, 2013, p.120-121;124).

O sociólogo português Boaventura de Souza Santos (2015, p. 27) traz uma importante contribuição para esta questão, a partir de suas pesquisas de cunho sociológico em relação aos mecanismos informais de solução de controvérsias, chamados de justiça popular pelo autor. Na verdade, esta contribuição vem ao encontro dos anseios dos operadores do direito que lutavam pela mudança daquela justiça retributiva para uma justiça restaurativa.

A justiça restaurativa vai além dos meios alternativos de resolução dos conflitos visto que ela se preocupa com o restabelecimento da paz social a partir do envolvimento da vítima com o agressor, a comunidade onde se praticouo delito e um terceiro imparcial que ajudará na construção do resultado almejado, ou seja, o acordo.

Vale destacar que, independentemente dos meios de resolução de conflitos utilizados pelas partes, a justiça restaurativa prevê e considera como objetivo primordial a voluntariedade das partes em restaurar a situação anterior ao dano, não através da pena, do castigo, mas sim, por meio da escuta dos personagens envolvidosno conflito, principalmente do relato da vítima e do pedido de perdão pelo agressor, após sentir, internamente, o mal que provocou, sem, contudo, necessitar da participação de órgãos jurisdicionais legalistas, a origem desta forma de justiça data de aproximadamente duzentos anos atrás, quando as comunidades tribais aplicavam procedimentos no sentido de obrigar os ofensores a reparar o dano, trabalhando para a família ofendida e devolvendo o que the havia roubado.

A preocupação sempre foi com a reparação do dano causado às vítimas e não castigar o ofensor. A primeira vez que se verificouuma solução alternativa baseada neste tipo de justiça nos tempos modernos foi em casos ocorridos com menores no Canadá e nos EUA, conhecidos como mediação vítima-ofensor (VOM).Inclusive, a Organização das Naçães Unidas (ONU), por meio da Comissão de Prevenção do Delito e 
Justiça Penal (2002), recomenda aos países membros a aplicação da justiça restaurativa no âmbito de seus sistemas de justiça penal, incluindo a habilitação das pessoas que participam em tais processos, a vítima, o delinquente e as comunidades na adoção de decisões por consenso, propiciando assim, uma nova maneira de pensar dos operadores do Direito Penal (COLORADO, 2013, p.122-123; 125).

Por outro lado, Lauro Ericksen Cavalcanti de Oliveira, no estudo Elementos sociológicos das modalidades alternativas de resolução de conflitos, descreve a justiça popular como sendo "uma forma de resolução de conflitos estruturada quase que inteiramente na informalidade de procedimentos e que alcança altos níveis de satisfação dentre aqueles indivíduos que dela se valem". O autor afirmaser preciso se comentar e se entender o que vem a ser conflito para poder "abordar com propriedade a questão dos mecanismos de resolução de conflitos", destacando que a única modalidade de conflito que foi de interesse na análise de seu estudo é a que trata dos conflitos interpessoais em sua instância individual (OLIVEIRA, 2016 p.4).

Assim, para o autor, "para que haja o conflito pressupõe-se que haja uma oposição de interesses entre aqueles que estão em um embate". Esse embate surge, segundo o autor, "quando alguém encontra um óbice para alcançar um bem que seja igualmente pretendido por outra pessoa, de modo que nenhuma delas possa conviver (ou ao menos possa tolerar tal fato) com a ausência do supramencionado bem da vida"Adiante, o mesmo autor comenta que "do ponto de vista sociológico, o Estado não detém o monopólio da produção e distribuição do direito". Para ele, a Sociologia vê a existência de outros mecanismos informais de resolução de conflitos que se articulam e convivem com os mecanismos formais reconhecidos pelo Estado (OLIVEIRA, 2016 p.4;6;18).

Já no artigo Alternativas de resolução de conflitos e justiça restaurativa no Brasil,Rodrigo Ghiringuelli de Azevedo e Raffaella da Porciúncula Pollamolla, comentam que "o envolvimento cada vez mais ativo do Estado na gestão dos conflitos e acordos entre classes e grupos sociais, levou à judicialização da vida social contemporânea" (AZEVEDO; POLLAMOLLA, 2016 p.175). Os autores constatam que num:

quadro de crescimento da violência, de desrespeito aos direitos civis e de incapacidade do sistema de justiça criminal para administrar a conflituosidade social, impõe-se o desafio de reestruturar esses mecanismos institucionais e buscar alternativas capazes de reduzir a violência e os danos causados pela ineficaz administração dos conflitos (AZEVEDO; POLLAMOLLA, 2016 p.180).

Defendem os referidos autores que "as práticas restaurativas fazem sentido e dependem de um contexto em que o conflito é visto como uma oportunidade de reconstrução, de estabelecimento de novas relaçães, novos entendimentos, sendo a sua resolução uma maneira de construir a ordem social"(AZEVEDO; POLLAMOLLA, 2016 p.183).

Os aspectos mencionados evidenciam o inter-relacionamento de fatores jurídicos e sociológicos que provocam impacto importante na vida das pessoas e fazem surgir novas concepções e visões em relação aos institutos jurídicos existentes que precisam ser estudados em interface com a Sociologia. Entre estas concepções, 
surge a que se refere à prevenção comunitária que significa "prevenção integradora, prevenção inclusiva que, que rechaça o castigo e propõe alternativas reconciliadoras e de reforma social, conceito um tanto difuso que se enlaça com o de solidariedade e controle coletivo" (GARCIA-PABLOS apudCOLORADO, 2013, p.110).

As cinco principais pretensões elencadas por Fernando Diaz Colorado (2013, p.126-128) são as seguintes:

1. Convidar à plena participação e ao consenso entre as partes - no sentido de não excluir a justiça tradicional, mas sim complementá-la. A justiça restaurativa propõe o encontro entre a vítima e o agressor, mediado pela pessoa capacitada. Esta participação deve ser de forma proativa, não reativa, nem vingativa; a participação da vítima é voluntária e, na maioria das vezes, também a do agressor. Com isso, ambos adquirem a condição de expressar seus sentimentos e crenças com relação ao conflito;

2. Sanar o que foi danificado - ao final do encontro, a vítima e o agressor deverão chegar a um acordo sobre como o agressor vai reparar os danos causados, inclusive de ordem econômica e emocional;

3. Buscar a responsabilidade completa e direta - não se trata de simplesmente encontrar culpados e castigálos, mas centrar o enfoque no dano e como poderá ser sanado, mediante o entendimento das consequências humanas acarretadas com o crime e abrir a possibilidade de criar novas relações humanas;

4. Reunir o que foi dividido - a solução do problema de maneira participativa é a essência da justiça restaurativa. Pretende-se que o delinquente perca esta condição à medida que se recupere, diante do enfoque restaurativo, integrando-se novamente à sociedade;

5. Fortalecer a comunidade para evitar danos maiores - o compromisso cooperativo é fundamental para que as partes cheguem a resultados benéficos para ambos, através das reuniões de restauração, denominadas círculos de sentença.

Como se percebe, a justiça restaurativa é rica em intenções de igualdade e de recuperação das partes envolvidas no conflito, ao se utilizar de meios alternativos com a presença das partes, as quais vão buscar meios de resolução eficazes, posto que partiram delas, pelo menos à busca da resolução.

\section{ATUAÇÃO DA ADMINISTRAÇÃO PÚBLICA EM JUÍZO}

A Administração Pública em juízo é caracterizada por ter um ente público numa das partes do litígio como autora ou como ré. Tanto num como em outro caso, ela se beneficia de prerrogativas processuais evitando fazer acordos que poderiam extrapolar os limites da vinculação com a lei. Com isso, os processos se tornaram mais lentos do que já eram, provocando custos, na maioria das vezes, que impactam os cidadãos. Segundo Brandão (2009), a falácia de que a Administração defende litígios que envolvem direitos indisponíveis, levando-a a estar 
impedida de fazer conciliação, é inconsistente. Entende-se que a demora provocada nas ações que não comportam acordos, sai mais cara do que a Administração gastaria com os acordos.

A Constituição Federal de 1988 assegura, pelo artigo 5, LXXVIII: "a razoável duração do processo e os meios que garantam a celeridade de sua tramitação". No entanto, a Emenda Constitucional n 45/2004, que inseriu este inciso na Constituição, não conseguiu garantir a referida celeridade, em virtude de não ter tratado, especificamente, da burocracia estatal, conhecida por todos como impeditiva da celeridade e da razoável duração do processo.

Será que o $\mathrm{CPC}$ em vigor, com a previsão dos instrumentos consensuais de resolução dos litígios (conciliação e mediação) vai conseguir superar a falácia dos direitos indisponíveis da Administração Pública? Pode-se argumentar que faltavam normas procedimentais como a conciliação e a mediação institucionalizada para tornar disponíveis os direitos da Administração Pública em juízo?

Na visão de Brandão (2009), o Direito Administrativo calcado no princípio da legalidade é atualmente insuficiente, ou seja, superado no Estado de Direito, pois não corresponde aos anseios do povo. A autora justifica essa perda de status quando menciona que o legislativo não tinha preocupação com o conteúdo das leis, pois se considerava legítimo representante de seus eleitores, o que lhe dava a liberdade de criar leis em completa dissonância com a evolução social, podendo-se dizer até leis inconstitucionais no nascedouro.

Outro ponto abordado por Brandão (2009) é que o Poder Judiciário leva a ideia de litígio, minimizando a possibilidade de se estabelecerem acordos, o que corrobora com o modelo falido a que assistimos atualmente no Judiciário e na dificuldade do poder público fazer acordos nas demandas em que é parte.Já Leonardo Carneiro da Cunha (2016, p.1) afirma que:

no caso da Fazenda Pública, é elementar sua submissão aos princípios e regras de direito público, sendo certo que, no direito público, vigoram o princípio da legalidade, a presunção de legitimidade dos atos administrativos, a autoexecutoriedade dos atos administrativos e a supremacia do interesse público sobre o privado.

Diante desta situação rígida e protetiva do interesse público, desde 2009 Brandão já apontava a necessidade de haver instâncias negociais que garantissem o contato entre autor e réu em ambientes onde pudessem ser discutidas suas pretensões, o que leva a pensar que o CPC trouxe com o comando do artigo 165:

Os tribunais criarão centros judiciários de solução consensual de conflitos, responsáveis pela realização de sessões e audiências de conciliação e mediação e pelo desenvolvimento de programas destinados a auxiliar, orientar e estimular a autocomposição.

O que se pôdeobservar ao longo desses treze anos após a Emenda Constitucional n 45/2004 e até a entrada em vigor do CPC atual foi a existência de medidas tímidas para arazoável duração dos processos, sem produzir efeitos nem conseguir mudar o atuar da Administração Pública, a ponto de lhes indicar o acordo como meio de agilizaçãodos processos e diminuição dos custos. $\mathrm{O}$ artigo $100, \mathbb{\$} 2^{\circ}$, da Constituição da República estabelece que os precatórios referentes aos 
débitos de natureza alimentícia cujos titulares tenham 60 (sessenta) anos de idade ou mais na data de expedição do precatório, ou sejam portadores de doença grave, definidos na forma da lei, serão pagos com preferência sobre todos os demais débitos até o valor equivalente ao triplo do fixado em lei para os fins do disposto no $\$ 3^{\circ}$ deste artigo, admitido o fracionamento para essa finalidade, sendo que o restante será pago na ordem cronológica de apresentação do precatório.

Entretanto, tal dispositivo constitucional não demonstra a eficácia desejada, uma vez que ocorre uma extensa fila de precatórios, resultantes de sentenças transitadas em julgado, cujo pagamento fica adiado por prazo indeterminado, prejudicando o jurisdicionado. Há casos que seus titulares morrem antes de receberem seus créditos.

Brandão (2009) dá notícia de que as desapropriações amigáveis e os termos de ajustamento de conduta (TAC) eram um tipo de solução de conflitos entre a Administração Pública e o particular. Por este olhar, a insuficiência destes instrumentos gerou, talvez, a previsão no CPC em vigor de mecanismos consensuais mais efetivos, com a participação dos envolvidos no litígio, na busca de superar as dificuldades mencionadas acima.

Perlingeiro defende a "atribuição constitucional da legitimidade ad causam a órgãos públicos dotados de independência e imparcialidade”, pois entende que, neste caso, não haverá violação ao princípio do acesso à justiça. Ponto de fundamental importância trazido por Perlingeiro é em relação à coisa julgada erga omnes gerada nas decisões das ações coletivas. Para ele, trata-se de "condição sinequa non à efetividade da prestação jurisdicional de natureza difusa ou coletiva no âmbito do contencioso judicial administrativo, desde que se garanta a representatividade adequada e a unidade da prestação jurisdicional” (TARTUCE, 2015, p. 935-936).

Mauro Cappellettiaborda mais outro cuidado que se refere à exigência de qualificação técnica para enfrentamento dos direitos difusos que se assemelha à figura do amicus curiae prevista no novo Código para proteger interesses da sociedade civil, numa prova de que a segunda "onda" ainda se mostra atual na teoria processual contemporânea (CAPPELLETTI; GARTH, 1998, p. 68). Carolina Tupinambá define este "terceiro especial" ou "terceiro qualificado" como sendo "sujeito que recebe diversas denominações variáveis pelo intuito de conciliar os pontos convergentes quanto as suas características e natureza jurídica no direito interno”. Segundo a autora, os elementos gerados por este terceiro, no processo, produto de sua atuação, vão influenciar as decisões do conflito (TUPINAMBÁ, 2011, p. 116-117).

Outros profissionais semelhantes ao amicuscuriae,no Direito americano, segundo Laura Nader, apareceram com a ADR que "estimulou o surgimento de equipes de negociação internacional, compostas por profissionais oriundos de vários campos: direito, economia, psicologia social, ciência política, psicoterapia”. A autora destaca que

o que esses negociadores tinham de novo não era o fato de praticarem a mediação ou a negociação - afinal, esses modelos de processamento de disputa vinham sendo utilizados havia muito tempo. O que eles tinham em comum era uma repugnância pelos processos antagônicos confrontantes, pelos tribunais como forma de lidar com os problemas das 
massas, pela justiça feita através de quaisquer métodos de vencer ou perder (NADER, 2011).

Uma concepção mais ampla foi denominada por Cappelletti na "terceira onda" como "novo enfoque de acesso à justiça”, pois tem a preocupação de reconsiderar interesses representados anteriormente de forma errada ou, sequer representados, cuja atenção está centrada em pessoas e procedimentos que processam e previnem conflitos nas sociedades modernas(CAPPELLETTI; GARTH, 1998, p. 68).

Paulo Cezar Pinheiro Carneiro (2000, p. 40) destaca que “a CLT deu ênfase à via de conciliação extrajudicial para dirimir conflitos, prevendo em título próprio a organização sindical, conferindo legitimação aos sindicatos para celebrar convenções ou acordos coletivos do trabalho”, em clara ampliação do acesso à justiça. Já ZoraideAmaral de Souza endossa e amplia essa corrente, quando afirma que a solução dos conflitos por meios alternativos devem existir em paralelo ao Judiciário, embora admita que, em muitas ocasiões, este último deixa de fazer justiça (SOUZA, 2004, p. 92).

Para Cappelletti "esses direitos frequentemente exigem novos mecanismos procedimentais que os tornem exequíveis. Esse enfoque, em suma, não receia inovações radicais e compreensivas, que vão muito além da esfera de representação judicial"CAPPELLETTI; GARTH, 1998, p. 69; 71).

Apesar de os autores divergiremem alguns aspectos, se verifica que todos se preocupam com a adoção de métodos eficazes de resolução de conflito, cujo modelo ideal é o destaque às pessoas envolvidas no litígio, sempre acompanhadas de outras que lhe façam a devida representação. Essa postura aponta para o fato de que não basta a intenção dos litigantes em resolver o problema posto na lide, mas que o sistema ainda se preocupa com procedimentos processuais intermediários para se alcançar aquela finalidade de pacificação.

\section{O INCENTIVO DA SOLUÇÃO DE CONFLITOS POR MEIOS ADEQUADOS TRAZIDOS PELO NOVO CPC}

Partindo, ainda, da premissa de que o juiz tem visões sociais e políticas que podem interferir em suas decisões, a exigência de um juiz ativo na nova teoria processual brasileira pode provocar a distorção entre aquele que decide com base na lei e aquele que baseia a decisão na sua experiência de vida. Este fato ficou implícito no CPC em vigor por meio da cooperação institucionalizada. Talvez a intenção do legislador tenha sido de acompanhar as ideias de John Rawls, ou seja, do conceito com que este autor concebeu a razão como "forma de articular planos e colocar fins em uma ordem de prioridade". A partir desse conceito, Rawls estabelece que a "razão pública é característica de um povo democrático: é a razão de seus cidadãos, daqueles que compartilham de um status de cidadania igual” (RAWLS, 2000, p. 261-306).

Aliás, para o autor, "o que se tem é que os valores políticos da razão pública fornecem à corte os fundamentos para a interpretação". Talvez os fundamentos garantissem o atuar compromissado do juiz com a 
efetividade do acesso à Justiça, reservando para cada um suas particularidades de criação das decisões individuais. Isto não significa que os juízes devam estar de acordo uns com os outros, nem tampouco que podem invocar sua própria moralidade particular ou geral, pois a "Constituição não é o que a Suprema Corte diz que ela é, e sim o que o povo, agindo constitucionalmente por meio dos outros poderes, permitirá à Corte dizer que ela é" (RAWLS, John, 2000, p. 287; 288).

Já Paulo Cezar Pinheiro Carneiro (2000, p. 11) aborda a possibilidade de modificação da lei humana, mencionando o entendimento de Santo Tomás de Aquino, ao afirmar que a lei não poderia ser modificada, ainda que houvesse mudanças na condição dos homens ou fosse transformada a noção de bem comum, sob pena de enfraquecê-la.

Santo Tomás de Aquino, porém, não influenciou a postulação de Dworkin quando critica "o positivismo no ponto em que este só admite a existência de Direito após os processos formais de normatização". Nem se aproxima da autorização para um juiz mudar uma regra estabelecida, como se pretende no novo Código de Processo Civil. Segundo Dworkin, o juiz poderia mudar uma regra estabelecida

quando há um princípio que justifique a modificação (devendo este princípio ter reconhecimento geral), levando em conta padrões relevantes que não pudessem ser ignorados pelo juiz, como por exemplo a supremacia do Poder Legislativo, a doutrina do precedente, a equidade etc. (DWORKIN, 2002, p. 28-29).

Aliás, "foi Aristóteles quem primeiro falou sobre a possibilidade de o juiz adaptar a lei à situação concreta", segundo menciona Paulo Cezar Pinheiro Carneiro que, no entanto, adverte: "é importante registrar, antecedente a esse pensamento aristotélico, o pensamento socrático, que trazia acenos a uma doutrina positivista, na medida em que pregava a estrita obediência à lei - para ele, esta última se confundia com a noção de justiça" (CARNEIRO, 2000, p. 5-6). O mesmo autor cita a discussão entre os filósofos gregos - positivistas e jusnaturalistas - quanto

a possibilidade de o juiz, no momento da aplicação da lei, reconhecer (ou ser influenciado) por comandos ideológicos, flexibilizar os limites da interpretação na sua aplicação, em função das exigências da sociedade naquele determinado momento, da evolução dos costumes, das regras de experiência daquela comunidade (CARNEIRO, 2000, p. 19).

O acesso à justiça pautado na informalidade da solução do conflito, por meio da cooperação das partes, indica a necessidade de se ficar atento às matérias de relevância, de certa forma complexas no seu interior, postas ao Judiciário, as quais ultrapassam a boa interpretação das leis. Isto porque o juiz, em seu novo papel ativo, se mobiliza aconduzir as partes à composição amigável rápida, desprezando a manifestação de outras pessoas ou entidades com poder de representação, as quais poderiam intervir na decisão com argumentos jurídicos competentes.

A intenção original do CPC em vigor parece trazer uma releitura do informalismo na resolução dos conflitos, por meio da cooperação institucionalizada, numa crescente construção do acesso à Justiça ampliado. O 
alargamento desse acesso justificou a criação das alternative dispute resolutions(ADR),uma "justiça informal", na visão de Laura Nader, que engloba programas que privilegiam a utilização de mediação e arbitragem, ou seja, a utilização de meios extrajudiciais para resolver os litígios (NADER, 2011).

A conferencista esclareceu que os Estados Unidos, nos anos 1960, chegaram à resolução alternativa de disputa (ADR), na medida em que "o país passou de uma preocupação com a justiça para uma preocupação com a harmonia e a eficiência, de uma preocupação da ética do certo e do errado para uma ética do tratamento, dos tribunais para a ADR". Caracteriza-se como uma justiça que promoveu o acordo, "mais que vencer ou perder, que substituiu o confronto pela harmonia e pelo consenso, a guerra pela paz, as soluções vencer ou vencer" (NADER, 2011).

Para discutir um ponto de vista divergente do tema estudado nesteartigo, vale lembrar a seguinte afirmativa de Paulo Cezar Pinheiro Carneiro com relação ao predomínio da mediação e da conciliação nos processos trabalhistas:

O Direito do Trabalho foi o ponto de partida do verdadeiro acesso à justiça - o seu significado, no que se refere aos direitos individuais, pela facilidade do acesso, pela prevalência da mediação e da conciliação, pela índole protetiva, em especial no que diz respeito ao ônus da prova, do trabalhador, e mais do que isso, a visão da defesa coletiva da massa trabalhadora (CARNEIRO, 2000, p. 21).

Laura Nader, porém, declara que existem críticos da ADR, os quais "descrevem a mediação/negociação como algo destruidor de direitos ao limitar a discussão do passado, proibir a ira e forçar o compromisso" (NADER, 2011). Por outro lado, conforme afirma o professor Edward A. Purcell Jr. em entrevista à Revista Consultor Jurídico,

se você é o autor da ação e sabe que o réu pode fazer você esperar por cinco anos para receber seu dinheiro, a melhor coisa a fazer, em certas circunstâncias, é negociar, abrir mão de parte do que avalia ser seu direito, para antecipar a resolução. Em outras palavras você troca dinheiro por tempo (PURCELLJUNIOR apudBALIARDO, 2011).

Quando perguntado pelo jornalista Rafael Baliardo sobre a espera na resolução de questões complexas, o professor apontou o risco do problema, se referindo à prática comum das partes assinarem contratos com juízes aposentados e com advogados mais experientes, com o fim de não irem ao tribunal e agilizarem o procedimento perante a lei, destacando que existem vantagens e desvantagens nessa posição. Purcell declarou que "você pode economizar tempo e dinheiro assim. Porém, muitas vezes, a simplificação pode levar a erros, a negligenciar certos aspectos do processo, que passam despercebidos". O professor remete à conclusão de que poderia haver um certo prejuízo na decisão diferente daquela tomada por um juiz no Tribunal, ao advertir: "Pode ocorrer que uma das partes saia, eventualmente, prejudicada. Não é sempre que o resultado obtido na negociação corresponde ao que ocorreria em um tribunal, em frente ao juiz"(PURCELL JUNIOR apudBALIARDO, 2011).

Indo ao encontro da opinião do professor Purcell, Pinheiro Carneiro anota que "não se pode deixar de consignar, contudo, que sempre existirá um núcleo de questões que terá seu foro de resolução no Judiciário" 
(CARNEIRO, 2000, p. 25). Para Laura Nader, "a regra é que a parte mais fraca vá em busca da lei e a mais forte prefira negociar". E a autora prossegue afirmando que "ser universal é, penso eu, uma perspectiva hegemônica da disputa. Uma hegemonia a que me refiro como ideologia da harmonia, uma harmonia coerciva, cuja função primária é a pacificação" (NADER, 2011).

O CPC em vigor inovou não nos métodos, mas sim no incentivo do uso desses métodos, com a perspectiva de promover a cooperação das partes envolvidas no litígio, propiciando que obtenham uma decisão de mérito justa e efetiva, em tempo razoável. Daí,a previsão do artigo 60 do CPC. A propósito, Mendes; Silva; Almeida (2016, p.8) fazem o seguinte comentário sobre o referido artigo:

Não há que se falar somente em um Estado-juiz que resolva a lide de um modo imparcial, mas, também, da imperiosa necessidade de serem observados os deveres de lealdade, boa-fé e cooperação por todos que, de qualquer forma, participam do processo para se permitir que alcance um resultado que o afaste da sucessão fria de atos e documentos, para torná-lo melhor no campo operacional e administrativo, de modo a promover uma prestação da tutela jurisdicional de qualidade.

Numa primeira leitura do CPC atualmente em vigor, pode-se pensar que o legislador, ao permitir a participação efetiva das partes em juízo juntas, no objetivo de resolver a lide em tempo razoável, tenha caído em contradição ao permitir a modificação dos prazos e procedimentos, quando se tratar de lide que admita a autocomposição, conforme expressa o artigo 190 daquele diploma legal. A referida inovação estará sempre sob a supervisão do juiz, (artigo 190, parágrafo único), a fim de se evitar abusos e nulidades, sem, no entanto, demonstrar a real duração do processo, o que justifica a mencionada contradição. Conforme consta, o artigo 190 considera o Estado-juiz encarregado da supervisão e controle do procedimento de acordo com as especificações da causa. "Os ajustes só poderão ser feitos quando resultarem em nulidade, abusividade e vulnerabilidade, aspectos atinentes ao caráter público" (MENDES;SILVA;ALMEIDA, 2016, p. 141-142).

Já no que se refere à fixação do calendário, o artigo 191 prevê a participação do juiz no estabelecimento de prazos para a prática dos atos processuais "o que será vinculativo às partes e ao julgador e sua alteração só deverá ocorrer em situações excepcionais e justificadas". [...] dispensada a sua intimação para o ato diante da sua prévia ciência da data de sua realização" (NEVES, 2015, p. 229).

Assim, a quase obrigatoriedade da audiência de conciliação ou mediação prevista no CPC em vigor e as diversas formas de colaboração das partes pretende diminuir o tempo da demanda com um resultado eficaz, produto da vontade das partes.

Concordando com o pensamento de Mendes; Hartman (2016), percebe-se que a intenção do legislador foi de abreviar "a distância entre a propositura da demanda e a realização da audiência". Segundo os autores, os procedimentos existentes no CPC em vigor para a resolução consensual de conflitos por conciliação, mediação e outros de teor semelhante, por via judicial ou extrajudicial, constroem uma solução em vez de adjudicá-la, abrindo a possibilidade de uma nova formatação do acesso à justiça, sem que haja vencedores ou 
vencidos. Trata-se de uma "nova sistemática na qual se adota o modelo "conciliação-defesa" em detrimento do fundamentado na "defesa-conciliação" (MENDES; HARTMAN, 2016).

\section{CONSIDERAÇÕES FINAIS}

Como se verifica, o tema deste artigobusca analisar as ferramentas de solução dos conflitos previstas no Código de Processo Civil atualmente em vigor, na perspectiva da ampliação de acesso à justiça, mas com a possibilidade de supressão de direitos e a necessidade ou não de um novo papel institucional para o juiz na atual forma de resolução de conflitos por meio de enfoques não judiciais, conforme os artigos mencionados no texto.

Para Gustavo Quintanilha Telles de Menezes, "o magistrado participa exclusivamente reconhecendo o potencial de autocomposição das partes e encaminha o caso para a adoção de meios alternativos de solução de conflitos, sem que isso comprometa o direito de acesso à justiça eà tutela judicial" (MENEZES, 2011, p. 185-186 - grifos do original).

Há que se ter cuidado, no entanto, com a mudança de perfil do juiz e com a imposição da mediação na resolução dos conflitos judiciais, por exemplo, pois o modelo pode munir o juiz de superpoderes, a ponto de ficar tentado a mitigar a autonomia da vontade das partes envolvidas no processo, como justificativa da resolução do conflito a todo custo, resultado da visão sobre o procedimento judicial como forma de reivindicação coletiva.

A solução de conflitos por meios não judiciais, neste contexto, resulta na obrigação de o Judiciário solucionar as demandas propostas excedendo sua competência, em nome do denominado ativismo judicial, ou seja, resolução dos conflitos com a reafirmação da efetividade do processo pormeio de cooperação, mesmo que isso represente uma ameaça ou mitigue a autonomia da vontade, às vezes inviabilizando os direitos das partes.

Percebe-se que não há elementos para convencer a perpetuação da jurisdição, em sua visão estatal, como única forma de resolução dos conflitos, mas sim estudar o quadro da resolução via informalismo e cooperação e entender o Judiciário com juízes ativos que não podem abandonar certas restrições, em nome da solução a qualquer custo, sob pena de invasão de esferas que lhes retire a legitimidade do seu atuar e viole a interdependência dos poderes, acarretando a supressão de direitos.

Com base na nova visão da teoria processual, o presentetema abre perspectiva para, também, enfocar as novas ferramentas processuais em suas funções ampliadas, de forma a se buscar respostas para as dúvidas que se instalam a partir do novo modelo. Para isso se faz imprescindível o entendimento da moderna técnica judicial colocada no Código de Processo Civil (CPC) e o conhecimento das decisões judiciais que englobam a resolução por meio do informalismo.

Um dos aspectos de relevância neste sentido é o entendimento da melhoria ou a constatação da disfunçãoda prestação jurisdicional, expressa na redução do acesso à justiça, tendo como elemento principal a autonomia do juiz na modificação e adequação do processo, aumento de prazos e inversão de produção de provas versusa cooperação das partes em litígio, sem a consciência de que poderão ter seus direitos ou parte deles suprimidos. Afinal, como disse Humberto Dalla 
Bernardina de Pinho: "não custa lembrar, apenas a jurisdição é monopólio do Estado e não a solução dos conflitos" (PINHO, 2005, p. 110).

No entanto, é preciso esperar os resultados da adoção dos instrumentos contemplados no Código de Processo Civil atualmente em vigor para observar e verificar se estas inovações terão eficácia no contexto brasileiro de acesso à justiça. Como se verifica pelo elenco de autores e suas proposições, o tema é bastante complexo e oferece uma vasta pluralidade de pontos de vista, ensejando o aprofundamento do estudo com base em outras opiniões que, via de regra, se despertarão à medida que forem aplicados os procedimentos derivados deste novo diploma legal.

O novo modelo de resolução de conflitos de interesses com a identificação de meios adequados numa perspectiva mais ampla do que somente a jurisdição, vem a confirmar que os princípios e valores constitucionais insculpidos no texto de 1988 se baseiam na observância dos fundamentos do Estado Democrático de Direito, com justiça social, dignidade da pessoa humana e efetivo acesso à justiça.

\title{
ACCEPTABLE DISPUTE-SETTLEMENT APPROACHES OF RESTORATIVE JUSTICE IN LIGHT OF BRAZIL'S NEW CIVIL PROCEDURE CODE
}

\begin{abstract}
This article's objective is to examine dispute-settlement options specified by Brazil's New Civil Procedure Code [NCPC] (2015), identifying, evaluating and discussing the cooperation it encourages between parties involved in lawsuits, and especially focusing both on approaches to settlements and arbitration and on its impact on stakeholders, highlighting the informal justice system and its repercussions concerning access to the courts. Along these lines, the present paper seeks to examine the consequences of such methods from the standpoint of restorative justice, as compared to retributive justice, using the concepts developed by doctrine. Furthermore, it employs characteristics related to Brazilian Public Administration as a parameter, seeking to assess models adopted before the new code came into effect. Based on such an assessment, we advocate discussing the viability of encouraging dispute settlements along the lines of those proposed by Brazil's New Civil Procedure Code.
\end{abstract}

Keywords: Civil Procedure Law; dispute settlement; settlement; arbitration; retributive justice; restorative justice; public administration.

\section{REFERÊNCIAS}

ARAGÃO, J. Guilherme de. A justiça administrativa no Brasil. Cadernos de Administração Pública. Rio de Janeiro: EBAP, 1955.

AZEVEDO, Rodrigo Ghiringuelli de; POLLAMOLLA, Raffaella da Porciúncula. Alternativas de resolução de conflitos e justiça restaurativa no Brasil. Revista USP. Disponível em: vol.10, no. 04, Rio de Janeiro, 2017.pp. 2745-2762 2760 
<http://www.revistas.usp.br/revusp/article/viewFile/87825/90746>. Acesso em: 2 jun. 2016.

BALIARDO, Rafael. A justiça americana é conservadora. Revista Consultor Jurídico. Disponível em: <http://supremoemdebate.blogspot.com/2011/02/justica-americana-e-conservadora.html $>$. Acesso em: 17 fev. 2011.

BRANDÃO, Marcella Araújo da Nova. A consensualidade e a administração pública em juízo. 2009. 108 f. Dissertação (Mestrado Profissional em Poder Judiciário) - Escola de Direito da Fundação Getúlio Vargas, Rio de Janeiro, 2009.

CAPPELLETTI, Mauro. Processo, ideologias e sociedade. T.II. Ediciones Jurídicas Europa. Buenos Aires: América, s/d.

CAPPELLETTI, Mauro; GARTH, Bryant. Acesso à justiça. Tradução e revisão: Ellen Gracie Northfleet. Porto Alegre: Sergio Antonio Fabris, 1998.

CARNEIRO, Paulo Cezar Pinheiro. Acesso à justiça; juizados especiais cíveis e ação civil pública: uma nova sistematização da teoria geral do processo. 2. ed. Rio de Janeiro: Forense, 2000.

CÉSPEDES, Livia; ROCHA, Fabiana Dias (Col.). Vademecum Saraiva. 22.ed.atual. ampl. São Paulo: Saraiva, 2016.

COLORADO, Fernando Diaz. Conflicto, Mediación y conciliación desde una mirada restaurativa y psicojurídico. Bogotá: Ibañez, 2013.

COUTOURE, Eduardo Juan. Introdução ao estudo do processo civil. Tradução: Mozart Victor Russomano. 3. ed. Rio de Janeiro: Forense, 1995.

CUNHA, Leonardo Carneiro da. A Fazenda Pública em Júzo. 13.ed. Rio de Janeiro: Forense, 2016.

FIGUEIREDO, Simone Diogo Carvalho (Coord.) Novo Código de Processo Civil anotado e comparado para concursos. São Paulo: Saraiva, 2015.

FONTAINHA, Fernando de Castro. Acesso à justiça: da contribuição de Mauro Cappelletti à realidade brasileira. 2. ed. Rio de Janeiro: Lumen Juris, 2009.

MENDES, Aluisio Gonçalves de Castro. Ações coletivas e meios de resolução coletiva de conflitos no direito comparado e nacional. 4. ed. rev. atual. ampl. São Paulo: Editora Revista dos Tribunais, 2014.

MENDES, Aluisio Gonçalves de Castro; HARTMANN, Guilherme Kronemberg. A Audiência de conciliação ou de Mediação no Novo Código de Processo Civil. Revista de Processo,v.253/2016, mar.2016.

MENDES, Aluisio Gonçalves de Castro; SILVA, Larissa Pochmann da; ALMEIDA, Marcelo Pereira de (Coord.). Novo Código de Processo Civil comparado e anotado. 3.ed. Rio de Janeiro: GZ, 2016.

MENEZES, Gustavo Quintanilha Telles de. A atuação do juiz na direção do processo. In.: FUX, Luiz (Coord.). O novo processo civil brasileiro direito em expectativa: reflexões acerca do Projeto do novo Código de Processo Civil. Rio de Janeiro: Forense, 2011. 
NADER, Laura. Harmonia coercitiva: a economia política dos modelos jurídicos. Disponível em: <http://www.anpocs.org.br/portal/...00.../rbs.26.02.htm>. Acesso em: 17 fev. 2011.

OLIVEIRA, Lauro Ericksen Cavalcanti de. Elementos sociológicos das modalidades alternativas de resolução de conflitos. Disponível em: <http://www.publicadireito.com.br/artigos/?cod=1eee58f7a5d6bd6d $>$. Acesso em: 2 jun. 2016.

PINHO, Humberto Dalla Bernardino de. Acesso à Justiça: efetividade do processo. In.: PRADO, Geraldo Luiz Mascarenhas (Coord.). Mediação: a descoberta de um velho aliado na solução de conflitos. Rio de Janeiro: Lumen Juris, 2005.

RAWLS, John. A ideia de razão pública. In.: O liberalismo político. Tradução: Dinah de Abreu Azevedo. São Paulo: Ática, 2000, p. 261-306.

SANTOS, Boaventura de Souza. A justiça popular em Cabo Verde: Sociologia crítica do Direito. Coimbra: Almedina, 2015.

SILVA, Ricardo Perlingeiro Mendes da. A impugnação judicial de atos administrativos na defesa de interesses difusos, coletivos e individuais homogêneos. Revista de Direito do Estado, Rio de Janeiro, ano 2, n. 7, jul./set. 2007, p. 923-924.

SOUZA, Zoraide Amaral de. Arbitragem - conciliação - mediação nos conflitos trabalhistas. São Paulo: LTr, 2004.

TARTUCE, Fernanda. Mediação nos conflitos civis. 2. ed. atual. ampl. São Paulo: Gen; Método, 2015.

TUPINAMBÁ, Carolina. Novas tendências da participação processual - o amicus curiae no anteprojeto do novo CPC. In.: FUX, Luiz (Coord.). O novo processo civil brasileiro (direito em expectativa): reflexões acerca do novo Código de Processo Civil. Rio de Janeiro: Forense, 2011.

Trabalho enviado em 15 de outubro de 2017. Aceito em 26 de outubro de 2017. 